\title{
Políticas y prácticas de movilidad en los primeros siglos del Tabasco novohispano \\ Poder real e imaginario
}

\section{Politics and Practices of Mobility in Early Colonial Tabasco Real and Imaginary Power}

\author{
Nicoletta MAESTRI \\ https://orcid.org/0000-0002-0058-7564 \\ Universidad Nacional Autónoma de México (México) \\ Instituto de Investigaciones Históricas \\ nicoletta.maestri78@gmail.com
}

\section{Resumen}

Tabasco, con su geografía fragmentada por una intricada red hidrográfica, así como por su bajo porcentaje demográfico, constituía en los primeros siglos del virreinato un paisaje que escapaba al control de las autoridades coloniales. A través del análisis de mapas y fuentes escritas, el presente estudio se propone desarticular las políticas de movilidad que subyacieron a la nueva organización sociopolítica de la región de Tabasco, así como poner en luz posibles prácticas de resistencia al nuevo orden colonial.

Palabras clave: Tabasco, políticas de movilidad, transporte, resistencia, navegación.

\begin{abstract}
The fragmented geography of Tabasco, characterized by challenging hydrography and low population levels, constituted a landscape at the onset of colonial domination that escaped from the direct control of the government authorities. Through the analysis of maps and written sources, the aim of this study is to disentangle the politics of mobility that underlay the new socio-political organization of the region and to highlight possible practices of resistance to the new colonial order.
\end{abstract}

Keywords: Tabasco, politics of mobility, transportation, navigation, resistance. 


\section{Introducción}

Alrededor de 1694 un pequeño grupo de familias mayas chontales, tributarias de Atasta de la Real Corona, en la provincia de Tabasco, huyen de su pueblo para escapar de un brote de sarampión y de los pesados tributos $\mathrm{y}$, viajando a lo largo de la laguna de Términos, se instalan cerca del antiguo asentamiento de Xicalango. Aquí viven varios años, tratando de mantenerse alejados de los piratas y cortadores de palo de tinte ingleses que, desde su base en la isla de Jamaica, se habían asentado en la laguna. Después de varios años las autoridades españolas mandan una expedición para capturarlos y devolverlos a Atasta, donde su huida había afectado la recaudación de tributo, y al mismo tiempo logran temporalmente desalojar a los ingleses de la laguna de Términos. ${ }^{1}$ Este episodio, descrito por José Manuel Chávez Gómez, deja entrever varios aspectos importantes acerca de las políticas de movilidad en la región de Tabasco y Campeche en los primeros siglos de la Colonia. Por ejemplo, a pesar de la organización política española, la cual implicaba la fundación de nuevas cabeceras, encomiendas y reducciones para controlar la producción económica y limitar el movimiento de la población nativa, en la práctica, la limitada autoridad directa en la región permitía: 1) la presencia y libre movimiento de corsarios europeos a lo largo de la costa y tierra adentro por lagunas y ríos; 2) "migraciones" continuas de pequeños grupos de población local hacia las montañas del sur para escapar del yugo de tributos y piratas. La región costera de Tabasco y Campeche emerge, en los documentos, como una región de frontera donde el control de las autoridades españolas no era tan firme. En este sentido, Tabasco, con su geografía fragmentada por una intricada red de ríos, esteros, y lagunas, así como por su bajo porcentaje demográfico, constituía en los primeros siglos del virreinato un paisaje que escapaba a un control sólido por parte de las autoridades coloniales y facilitaba unas prácticas y políticas de movilidad más fluidas de lo que las fuentes presentan.

Con el término "políticas de movilidad" me refiero a un conjunto de relaciones de poder que subyacen a la organización y al acceso diferencial

${ }^{1}$ José Manuel A. Chávez Gómez, "Waterways, Legal Ways and Ethnic Interactions. The Rios District of Tabasco during the Seventeenth and Eighteenth Centuries”, en E. R. Medrano y S. Kellogs, eds., Negotiations within Domination. New Spain's Indian Pueblos Confront the Spanish State (Boulder: University Press of Colorado, 2010), 209-211. 
del movimiento. ${ }^{2}$ Estas políticas de movilidad siempre son históricamente definidas y se pueden entender sólo estudiando el contexto sociocultural en el cual el movimiento, sus narrativas, representaciones y prácticas se desenvuelven. La movilidad, siguiendo una tendencia reciente en las ciencias sociales, incluye prácticas sociales relacionadas con la circulación de gente, bienes e ideas, y sus razones subyacentes. ${ }^{3}$ Lejos de ser una superestructura neutral, desligada de las condiciones históricas contingentes, la movilidad, en la corriente de los mobility studies, es considerada un aspecto de las políticas y negociaciones que moldean la organización social de una región en una determinada época. ${ }^{4}$ Los defensores de esta tendencia enfatizan los cambios sociales y del paisaje a lo largo del tiempo y reconocen la existencia de múltiples perspectivas, incluyendo a varios actores (los que tenían libertad de movimiento, los que estaban forzados a moverse y quienes tenían una movilidad limitada o controlada) y, por ende, este enfoque pone particular atención a las relaciones de poder.

Desde esta perspectiva, el objetivo del presente estudio es dilucidar las políticas de movilidad que subyacen a la nueva organización sociopolítica de la región de Tabasco-Campeche en los primeros siglos de la historia novohispana, abordando las siguientes preguntas: ¿Cómo cambia la organización de la circulación fluvial y la relación de las poblaciones locales con su entorno a raíz del nuevo orden colonial? ¿Qué continuidades y rupturas hay? ¿Cómo se apropian los europeos del espacio geográfico en cuestión y cómo controlan el movimiento sobre este paisaje?

Para abordar estas preguntas, el presente trabajo pretende analizar algunos documentos históricos, mapas, relaciones geográficas, diarios de viajeros y eclesiásticos, en cuyas entrelíneas emergen aspectos ligados al movimiento, para interpretarlos a través de la lente de los estudios de movilidad. Entender las políticas de movilidad de la primera época colonial en la región de Tabasco-Campeche puede arrojar nueva luz sobre procesos históricos de más amplia duración; por ejemplo, la reorganización social, y económica, y posibles estrategias de resistencia existentes en el sistema novohispano.

2 Tim Cresswell, “Towards a Politics of Mobility”, Environment and Planning D: Society and Space, 28 (2010): 17-31, DOI: 10.1068/d11407.

3 Tim Cresswell, "Towards a Politics"; Mimi Sheller y John Urry, “The New Mobilities Paradigm”, Environmental and Planning A, n. 38 (2006): 207-226. DoI: 10.1068/a37268; John Urry, Mobilities (Cambridge: Polity Press, 2007).

${ }^{4}$ Cresswell, "Towards a Politics", 26 
El término "políticas de movilidad" describe una serie de relaciones sociales que subyacen a la organización y al acceso diferencial al movimiento, sus narrativas y experiencias; también incluye la falta o la limitación de la circulación; por eso, un estudio de la movilidad debería considerar aquellas infraestructuras, prácticas, discursos y relaciones de poder que organizan, facilitan o bloquean el libre flujo de gente, objetos e ideas. ${ }^{5}$ Sin embargo, estas políticas de movilidad, según Tim Cresswell, una vez constituidas, no son fijas, más bien, se moldean dependiendo de las cambiantes relaciones y negociaciones sociales. ${ }^{6}$ En varios contextos históricos, la capitalización del movimiento ha constituido una estrategia fundamental en la organización de las relaciones sociales. Siguiendo a teóricos como Michel Foucault, varios trabajos han tratado de desentrañar las relaciones de poder implícitas en el acceso al movimiento a través del control sobre el territorio. ${ }^{7}$ En este sentido, me parece útil el concepto de "poder de" y de "poder sobre", 8 y aplicarlo al movimiento. Si consideramos al movimiento como una práctica social, podemos hablar de poder de movimiento y poder sobre el movimiento. Al primero lo considero como la habilidad y el derecho al movimiento, también como forma de resistencia a otras prácticas sociales; mientras que el poder sobre el movimiento es una fuerza coercitiva que se materializa a través de controlar, limitar, forzar o dirigir el movimiento. Esta fuerza coercitiva puede tomar formas materiales o inmateriales y se puede cumplir con una serie de prácticas o estrategias por parte de diferentes actores sociales.

En el contexto de la Nueva España, Nancy Farriss afirma que:

Las haciendas españolas se desarrollaron y crecieron tan lentamente en Yucatán que, durante la mayor parte de la época colonial (y en algunas regiones hasta mucho después), había gran cantidad de tierras y espacios baldíos. Los mayas podían

${ }^{5}$ Cresswell, “Towards a Politics", 21; Mimi Sheller y John Urry, "The New Mobilites Paradigm".

${ }^{6}$ Cresswell, "Towards a Politics", 21.

${ }^{7}$ Cfr. Jeremy W. Crampton y Stuart Elden, comp., Space, Knowledge and Power. Foucault and Geography (Aldershot, UK: Ashgate, 2007); James Delle, "Power and Landscape: Spatial Dynamics in Early-Nineteenth Century Jamaica”, en M. O'Donovan, ed., The Dynamics of Power, Occasional Paper n. 30 (Carbondale: Southern Illinois University Carbondale, Center for Archaeological Investigations, 2002), 341-361.

${ }^{8}$ Daniel Miller y Christopher Tilley, "Ideology, Power and Prehistory: An Introduction", en D. Miller y C. Tilley, ed., Ideology, Power and Prehistory (Cambridge: Cambridge University Press, 1984), 1-15, DOI: 10.1017/CBO9780511897443. 
circular con facilidad y lo hacían, y los pueblos de otras regiones de Mesoamérica parecen haber tenido una movilidad semejante, aunque en menor grado. ${ }^{9}$

Es decir, las diferencias geográficas y políticas al interior del vasto territorio de la Mesoamérica del siglo XVI, así como el desfase en los tiempos de conquista y colonización entre las varias regiones, permitieron que en el primer siglo de formación de la Nueva España, el control sobre los espacios conquistados se manifestara de manera diferente. Como se discute en el siguiente apartado, las características geográficas, económicas y demográficas de las regiones de Tabasco y Campeche, moldearon una política colonial que, si por un lado llevó a la creación de unos territorios con fronteras porosas, por el otro resultó en un interés más intenso en controlar la movilidad de la poca población sobre amplios terrenos baldíos. Estos últimos se transforman en áreas de refugios para los indígenas inconformes con el régimen colonial, y otros actores sociales, a través de prácticas de resistencia.

Varios elementos en las fuentes documentales y en la historiografía de Tabasco hacen entrever la importancia sobre el control de movimiento. Una de las características de la conquista y colonización de esta provincia es la importancia de su conformación geográfica para plasmar prácticas y legislaciones. Después de la ilusión inicial de la presencia de metales preciosos, fue claro para los españoles que Tabasco no abundaba en ninguna manera de las fortunas con las cuales fantaseaban. Su territorio se caracteriza, ahora como en la Colonia, por llanuras bajas inundables y una compleja red hidrográfica de ríos, lagunas y pantanos, ceñidas al sur por las primeras estribaciones de la Sierra de Chiapas. Este paisaje, que había sido aprovechado por los mayas chontales y otros grupos indígenas, creando una importante red de comercio local e interregional, con el altiplano de México, así como con áreas de Centroamérica, no constituía para la mentalidad española un lugar altamente rentable. Fue claro desde temprano en el proceso colonizador que la única riqueza presente en estos territorios eran los amplios terrenos cultivables, el cacao y las mismas poblaciones nativas como fuerza de trabajo o esclavos para los mercados de Europa y el Caribe. Paulatinamente, a estas actividades se fueron añadiendo las grandes estancias de ganado, sobre todo vacuno, que caracterizarán la economía

\footnotetext{
${ }^{9}$ Nancy Farriss, La sociedad maya bajo el dominio colonial, Artes de México (México: Consejo Nacional para la Cultura y las Artes, Instituto Nacional de Antropología e Historia, 2012), 21.
} 
de Tabasco en los siglos posteriores. ${ }^{10}$ En este panorama, la creación y la implementación excepcionalmente larga de encomiendas y las reducciones de poblaciones se pueden interpretar como una política de movilidad enfocada a limitar la circulación de la población nativa y concentrar y capitalizar su fuerza de trabajo. Otro cambio importante en la organización del territorio en el Tabasco colonial fue, según Martín Ortiz, una creciente preponderancia de los caminos terrestres a expensas de las rutas fluviales. ${ }^{11}$ En su investigación, el autor recolectó amplia información acerca de la abertura y mantenimiento de nuevos caminos en la época virreinal, con un creciente desinterés en las rutas fluviales. En el primer siglo de la Colonia, los españoles dominaron sólo marginalmente las técnicas de transporte nativas, navegación en ríos y el uso de canoas, más bien se aprovecharon del trabajo y el conocimiento de los indígenas para moverse y controlar el territorio, para luego adaptarlo a sus nuevas necesidades. Aunque es posible que la preferencia española por vías de comunicación terrestres, aunado a la progresiva baja de población indígena y abandono de las zonas costeras por su creciente inseguridad, haya socavado la importancia de la comunicación fluvial, como propone Ortiz, ${ }^{12}$ también es posible que las prácticas indígenas simplemente hayan encontrado un menor espacio en los documentos oficiales, y que se hayan mantenido por un tiempo más largo de lo que las fuentes sugieren. Es notoria la escasez de fuentes documentales acerca de la historia indígena de Tabasco, y esta laguna abarca también la organización del transporte. ${ }^{13}$ Veremos en algunos de los ejemplos cómo la movilidad fluvial y costera se mantuvo para las poblaciones originarias

${ }^{10}$ Mario Humberto Ruz, Un rostro encubierto. Los indios del Tabasco colonial (México: Centro de Investigaciones y Estudios Superiores en Antropología Social, 1994), 64-65; Mario Humberto Ruz, Los linderos del agua. Francisco de Montejo y los orígenes del Tabasco colonial (Villahermosa: Gobierno del Estado de Tabasco, 1991); Francisco Jiménez Abollado, Entre ríos, pantanos y sierra. Marginalidad y subsistencia en la provincia de Tabasco (1517-1625), edición Kindle (Sevilla: Editorial Universidad de Sevilla, 2015), posición: 4123, 4130, 4137.

${ }^{11}$ Martín Ortiz, Los caminos de Tabasco. Las vías de comunicación terrestre y la historia de Tabasco desde la época prehispánica hasta 1850 (Villahermosa: Gobierno del Estado de Tabasco, 1988), 14-15, y 34.

12 Ortiz, Los caminos de Tabasco, 47.

${ }^{13}$ Ruz menciona varias razones posibles para la escasez de fuentes del primer siglo de la Colonia en Tabasco: naturales, como el clima húmedo que no facilita la preservación de documentos de archivo, y culturales, los numerosos cambios de ubicación de la capital tabasqueña, y por ende de sus archivos oficiales; los ataques piratas y consecuentes incendios de edificios gubernativos en Santa María de la Victoria y Villahermosa. Cfr. Ruz, Un rostro encubierto, 18-20. 
como un importante sistema de transporte y de trabajo por lo menos en la primera época colonial.

Otro cambio en el sistema de movilidad de Tabasco fue el progresivo abandono de la costa, primero a través del despoblamiento de los centros prehispánicos, a causa de las epidemias y de la ruptura de la red de intercambio marítima. En un segundo tiempo, el frecuente acoso de piratas y las condiciones insalubres provocaron un desplazamiento de las poblaciones hacia las zonas serranas del sur. Este proceso de abandono hizo que la región costera se convirtiera, desde finales del siglo XVI, en un blanco fácil para piratas y corsarios europeos que trataban de infiltrarse en la rica red de comercio de monopolio de la Corona española. En conclusión, la costa de Tabasco pasó de ser un área importante de transporte y comercio a finales de la época prehispánica a ser una frontera olvidada, pobre y despoblada de la Nueva España.

Los cambios en la organización del territorio, de la infraestructura y rutas de transporte, no fueron la única estrategia de control sobre la movilidad. El declive poblacional general, debido a epidemias y abusos, hizo que las autoridades políticas y eclesiásticas trataran de limitar la movilidad de los indígenas, no solamente con las políticas de reducciones, congregando a pueblos que anteriormente permanecían separados, sino también con prácticas hacia grupos sociales específicos, obligando, por ejemplo, a las mujeres a moverse para trabajar al servicio de los españoles como sirvientas, y a los canoeros indígenas a transportar, a veces forzosamente, primero a las huestes de conquistadores y luego las mercaderías de los españoles. En este último caso, hay evidencia de que en algunas circunstancias, los transportadores fueran vendidos como esclavos junto con la carga hacia los puertos del Caribe y Europa. ${ }^{14}$

Hasta ahora se han descrito algunas de las estrategias de la Corona para ejercer el poder sobre el movimiento. Sin embargo, las mismas características del territorio tabasqueño - amplias áreas despobladas, una intricada red fluvial, fronteras porosas con los colindantes territorios insumisos de la montaña, una general baja densidad de población, y la lejanía de los principales centros de poder colonial (político y eclesiástico) - limitaron la capacidad de control directo sobre su territorio, dejando un amplio espacio para prácticas de resistencia. Es decir, el poder de movimiento se manifestó a través de la huida hacia zonas de refugio, como las áreas de selva al sureste, conocidas

${ }^{14}$ Ruz, Un rostro encubierto, 64-65. 
como las montañas o "el despoblado", y a las zonas de pantano alrededor de la laguna de Términos, áreas sólo nominalmente bajo el dominio colonial.

A continuación, se presentan algunos documentos, tales como relaciones oficiales, diarios, cartas y mapas donde las informaciones acerca de la infraestructura, medios, prácticas y narrativas del movimiento se entrelazan para reconstruir la política de movilidad de esta región en la primera época colonial. El análisis de la manera en que estas políticas fueron aprovechadas o resistidas por los varios actores involucrados puede arrojar una visión más fluida sobre las relaciones y negociaciones sociales que subyacen a varios aspectos de la historia novohispana de Tabasco.

Infraestructura y medios de transporte: el sistema de movilidad

El primer elemento por analizar para entender las políticas de movilidad es el sistema de movilidad; es decir, la infraestructura y medios de transporte en uso en un determinado tiempo y espacio. ${ }^{15}$ Ya vimos cómo antes de la llegada de los españoles la región de Tabasco era un territorio interconectado, gracias a la importancia de su red comercial. Desde épocas antiguas había un sistema de comunicación terrestre, marítimo y fluvial que conectaba esta región con el altiplano de México, Yucatán y Centroamérica. ${ }^{16}$

Asentamientos como Potonchán, capital de los mayas chontales, en la desembocadura del río Grijalva; Xicalango, importante puerto de intercambio con fuerte presencia mexica en la laguna de Términos, y Los Cimatanes, en el extremo meridional de la Chontalpa, cerca de la confluencia de los ríos Grijalva y Cunduacán, eran los más importantes entre los nodos de comercio y comunicación donde convergían rutas terrestres y acuáticas ${ }^{17}$ (véase el mapa 1).

15 Urry, Mobilities, 12-16.

16 Thomas A. Lee, “The Historical Routes of Tabasco and Northern Chiapas and their Relationship to Early Cultural Development in Central Chiapas”, en Thomas A. Lee y Carlos Navarrete, coords., Mesoamerican Communication Routes and Cultural Contacts. Papers of the New World Archaeological Foundation n. 40 (Provo, Utah: Brigham Young University, New World Archaeological Foundation, 1978), 49-66; Ernesto Vargas Pacheco y Lorenzo Ochoa, "Navegantes, viajeros y mercaderes: notas para el estudio de la historia de las rutas fluviales y terrestres entre la costa de Tabasco-Campeche y tierra adentro”, Estudios de Cultura Maya, v. 14 (1982), 69-118, DoI: 10.19130/iifl.ecm.1982.14.551.

${ }_{17}$ R. C. West, N. Psuty y B. G. Thom, Las tierras bajas de Tabasco en el sureste de México (Villahermosa: Gobierno del Estado de Tabasco, 1985). 


\section{Mapa 1}

Provincia de Tabasco Y Regiones Colindantes, CON PUEBLOS MENCIONADOS EN EL TEXTO Y LOCALIDADES MODERNAS

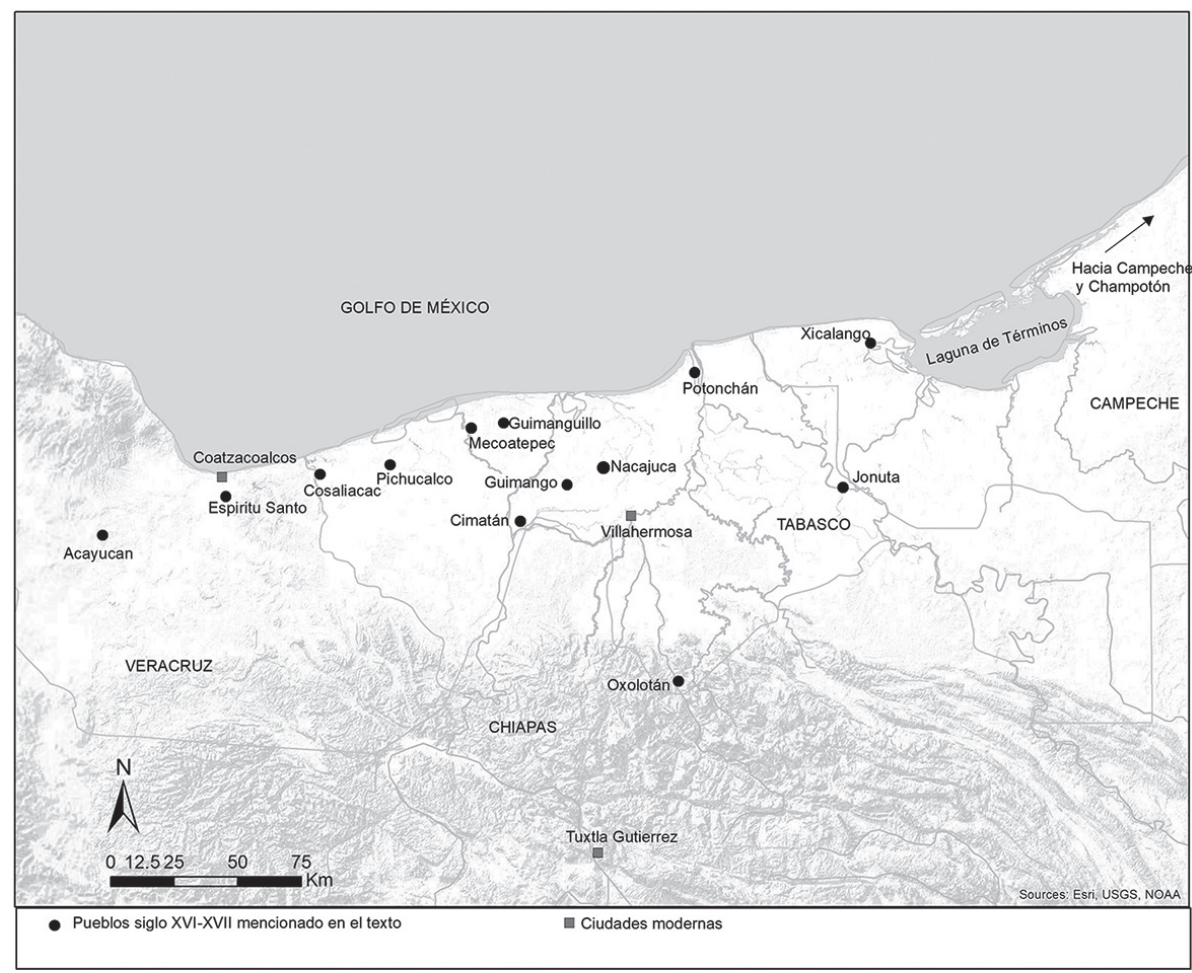

FuEnte: De la Garza et al., Relaciones histórico-geográficas; West et al., Las tierras bajas de Tabasco. Elaboración de la autora.

Las principales eran una ruta interior, que empezaba en Coatzacoalcos y llegaba hasta la Chontalpa, conectando varios pueblos (Ocuapan, Mecatepec, Ostitán y Pichucalco); otra ruta tierra adentro salía desde Acayucan, en Veracruz, llegaba a Huimanguillo y aquí se dividía en un tramo que continuaba hacia el sur y la sierra, llegando a Chiapas, y otro que continuaba al este hacia Yucatán. ${ }^{18}$

La segunda ruta era la vía costera, que partiendo de la villa de Espíritu Santo, continuaba hacia el este, cruzando los Ahualulcos, la Chontalpa hasta Yucatán, conectando asentamientos costeros como Potonchán, Xicalango, 
Champotón, Campeche y Cabo Catoche. Esta ruta, que tenía un ramal hacia el sur, conectándose con el asentamiento de Itzamkanak, sobre el río Candelaria, era el camino seguido por los pochtecas mexicas, y por Cortés en su viaje de 1524-1525 hacia Las Hibueras (Honduras) para apagar la sublevación de Cristóbal de Olid. ${ }^{19}$ El camino probablemente pasaba sobre los terrenos más altos y secos a lo largo de los antiguos cordones litorales, y fue tomado por Cortés y sus numerosos acompañantes por ser el más adecuado para huestes con caballos. La misma ruta fue utilizada por Bernal Díaz del Castillo y Rodrigo Rangel en su entrada a los Cimatanes para someter a esas poblaciones. ${ }^{20}$

Conquistadores como Cortés y Díaz del Castillo fueron los primeros en aportar información acerca del sistema de movilidad de Tabasco. Frecuente es la mención en sus escritos de tener que mezclar medios de transportes de tradición indígena y europea. La práctica de utilizar animales de carga, en primer lugar caballos, que se mueven con dificultad en terrenos pantanosos, hace que desde su llegada, los españoles tuvieran que negociar medios de transporte conocidos con un paisaje novedoso, combinando el uso de caballos, canoas y la construcción de puentes. ${ }^{21}$

En la quinta carta escrita por Cortés al emperador Carlos V, encontramos cierta información valiosa acerca de la organización de la movilidad para los primeros momentos de la conquista. Es claro que en estas primeras experiencias, los españoles se apoyaran completamente en el sistema de movilidad, y en la infraestructura indígena. La tradición europea de transporte "choca" con la infraestructura y la geografía locales, y en varios puntos del texto hay comentarios acerca de la impracticabilidad de los caminos. Al mismo tiempo, los españoles "fuerzan" en el territorio su sistema de movilidad, abriendo brechas, caminos nuevos y construyendo puentes. ${ }^{22}$

Cortés describe Tabasco como: "tierra muy baja y de mucha ciénega; tanto que en tiempo de invierno no se puede andar, ni se sirven sino en canoas y con pasarla yo en tiempo de seca, desde la entrada hasta la salida

${ }^{19}$ Cortés, Quinta Carta de relación.

${ }^{20}$ Ciprián Cabrera Bernat, Viajeros en Tabasco. Textos (Villahermosa: Gobierno del Estado de Tabasco, 1987), 70; France V. Scholes y Ralph L. Roys, Los chontales de Acalan-Tixchel (México: Universidad Nacional Autónoma de México, Instituto de Investigaciones Filológicas, Centros de Estudios Mayas; México: Centro de Investigaciones y Estudios Superiores en Antropología Social, 1996), 86.

${ }^{21}$ Scholes y Roys, Los chontales..., 85.

${ }^{22}$ Cabe la posibilidad de que estos puentes fueran de balsas. 
de ella se hicieron más de 50 puentes". ${ }^{23}$ El conquistador es atento en mencionar al monarca que abrió muchos caminos "donde antes no había ninguno", ${ }^{24}$ ya que "en toda aquella tierra no se hallaba camino para ninguna parte, [...] porque todos se sirven por el agua a causa de los grandes ríos y ciénegas que por la tierra hay". ${ }^{25}$

En varios puntos de su descripción menciona que desde numerosos pueblos llegaban en canoas para ayudarlos a cruzar los ríos, y en caso de no encontrar canoas disponibles, los españoles y sus guías se sirvieron de la construcción extemporánea de balsas.

Por ejemplo, al cruzar a caballo el río Mazapa (el río Dos Bocas, actualmente río Seco) en la cercanía del actual Paraíso, Cortés afirma que con "una canoa y con balsas que hicieron de madera comencé a pasar el fardaje por aquel río". ${ }^{26}$

A pesar del mapa o "figura" proporcionado a Cortés por los señores de Xicalango y Potonchán, se repiten en el texto las voces de los pueblos encontrados en el camino, que afirman que "por tierra no se podía andar". ${ }^{27}$ Sería interesante reflexionar si estas afirmaciones no hayan sido, en algunos casos, una estrategia por parte de los indígenas para disuadir al conquistador a continuar con la misión, más que una verdadera falta de conocimiento de rutas alternativas terrestres.

Una vez concluida la fase de conquista, y empezada la colonización, las autoridades españolas de Tabasco impulsaron la ampliación de las rutas terrestres existentes a Yucatán, Chiapas y Coatzacoalcos, y crearon nuevos caminos más acordes a sus medios de transporte, para integrar las varias regiones productivas de la región. ${ }^{28}$ Por esta razón, y por el progresivo aumento de suelos pantanosos, para finales del siglo XVI, "la ruta costera de Cortés" había caído en desuso, y se estaba impulsando, en su lugar, "la ruta de Tierra Adentro". ${ }^{29}$ Ésta, como hemos visto, iba desde la Villa de Espíritu Santo, a la Chontalpa, y aquí se dividía en un ramal que iba hacia la Sierra de Chiapas al sur y otro que continuaba hacia Campeche y Yucatán,

\footnotetext{
${ }^{23}$ Cortés, Cartas de relación, 223.

${ }^{24}$ Cortés, Cartas de relación, 225.

${ }^{25}$ Cortés, Cartas de relación, 225.

${ }^{26}$ Cortés, Cartas de relación, 224.

${ }^{27}$ Cortés, Cartas de relación, 223.

28 Ortiz, Los caminos de Tabasco, 34.

${ }^{29}$ Ortiz, Los caminos de Tabasco, 34.
} 
facilitando el transporte no sólo entre Chiapas y Tabasco, sino de Guatemala, vía Huehuetenango, a Coatzacoalcos. ${ }^{30}$

Un testimonio importante de este proceso se puede encontrar en el conocido texto de las Relaciones histórico-geográficas de la alcaldía mayor de Tabasco, el cual incluye la Relación de la Provincia de Tabasco y la Relación de la Villa de Santa María de la Victoria. ${ }^{31}$ Las Relaciones histórico-geográficas son documentos en su mayoría redactados en las últimas décadas del siglo XVI, bajo petición del rey Felipe II. Éstas constituyen la respuesta a una encuesta de 50 preguntas enviadas a los funcionarios coloniales para conocer la historia, la geografía, los recursos naturales, la infraestructura y la demografía de los territorios de ultramar. Algunos de estos documentos cumplieron con el requisito de ser acompañados por "pinturas" que representaran los espacios coloniales. Esta empresa respondía a una voluntad imperial de proyectar una imagen unificada y de legitimación sobre los territorios conquistados. ${ }^{32}$

La Relación de Tabasco, completada en 1579 por el alcalde mayor Vasco Rodríguez, está acompañada por el famoso mapa circular atribuido a Melchor de Alfaro Santa Cruz, encomendero de los pueblos de Guavizalco y Tabasquillo. El texto sobre la provincia de Tabasco presenta datos importantes acerca del sistema de movilidad en la región en la primera época colonial, mencionando, por ejemplo, cuales ríos son navegables, el estado de los caminos terrestres y la existencia de algunos pueblos donde se encuentra personal especializado en el transporte de viajeros y comerciantes de un lado al otro de los ríos. Por ejemplo, el punto siete de la Relación, que describe la distancia entre la provincia de Tabasco a la ciudad de Mérida, menciona: "Hay de esta provincia a la ciudad de Mérida, donde está la catedral, ciento y veinte leguas de esta provincia, poco más o menos; van por la mar costeando; también hay camino por tierra que es muy trabajoso..." 33

En el segundo texto, relativo a la Villa de la Victoria, la respuesta a la pregunta ocho de la encuesta, que se refiere a la distancia entre los varios asentamientos de españoles, dice:

30 Ortiz, Los caminos de Tabasco, 34.

${ }^{31}$ Mercedes de la Garza, Ana Luisa Izquierdo y María del Carmen León, ed., Relaciones histórico-geográficas de la alcaldía mayor de Tabasco. Relación de la provincia de Tabasco, Relación de la villa de Santa María de la Victoria (Villahermosa: Representación del Gobierno del Estado de Tabasco en México, 1988).

${ }^{32}$ Raymond B. Craib, "Cartography and Power in the Conquest and Creation of the New Spain”, Latin American Research Review, v. 35, n. 1 (2000), 16-17.

${ }^{33}$ De la Garza et al., Relaciones histórico-geográficas, 20. 
Está la villa y puerto de San Francisco de Canpeche [Campeche], de la dicha provincia de Yucatán, cincuenta leguas de esta villa poco más o menos por la mar, a causa de que por tierra no se camina por se haber despoblado el pueblo de Xicalango que estaba sobre unas lagunas, y en este pueblo se daba el avío necesario de comida y canoas para ir a atravesar unas lagunas que dicen de Términos e ir al pueblo de Tichel [Tixchel], de la dicha provincia de Yucatán. Este pueblo de Xicalango era una de las fuerzas de Montezuma [Moctezuma], y por estar despoblado este dicho pueblo se va por el rodeo referido en el segundo capítulo, y así el camino común y ordinario es por la mar de aquí a la villa y puerto de Canpeche [Campeche], el cual está a la parte del este. ${ }^{34}$

Estos dos fragmentos refuerzan una idea de movilidad propia de los españoles, es decir, principalmente vía terrestre. El hecho de que el sistema de movilidad indígena priorizara una circulación acuática hace que los nuevos ocupantes del territorio transmitan una percepción de este territorio como inviable y de difícil acceso.

Otro aspecto que sobresale en las Relaciones histórico-geográficas es la mención de medios e infraestructura de apoyo a la navegación. En un pasaje que habla de la isla de Chiltepec, cerca de la desembocadura del río Dos Bocas, se dice:

Está sobre esta boca de Dos Bocas, en la misma isla de Chiltepec, una casa en que asisten tres y cuatro indios que sirven de pasar el dicho río en unas canoas a los pasajeros que por ahí van y vienen de la Nueva España o Guazacualco [Coatzacoalcos] a esta dicha villa, a los cuales se les paga conforme a lo que ahí en un arancel les tiene tasado la justicia, y en aquella casa se acogen y albergan los viandantes [...] Prosiguiendo al oeste la costa adelante, a seis leguas, está otro río y puerto que se dice Copilco [....] es despoblado este río; fórmase de unas ciénegas y pantanos que vienen de la tierra adentro; están unos poblezuelos arredrados de este río la tierra adentro como cuatro leguas, seis y ocho, que se dicen los Copilcos, de los cuales proveen de lo necesario a tres indios que asisten en el río de Copilco para pasar, según que los de Dos Bocas, para lo cual tienen sus canoas ahí. ${ }^{35}$

Es evidente que la organización del transporte fluvial sigue a cargo de los indígenas, los cuales, a pesar del impulso dado por las autoridades al desarrollo de los caminos terrestres, mantienen un papel clave en el sistema de movilidad de la región, a través de los medios tradicionales de navegación

\footnotetext{
${ }^{34}$ De la Garza et al., Relaciones histórico-geográficas, 43.

${ }^{35}$ De la Garza et al., Relaciones histórico-geográficas, 46.
} 
en canoas. En este sentido, el texto abunda en referencias al hecho de que varias partes de la región no son transitables sino en canoas u otras embarcaciones. Esto hace vislumbrar un proceso de apropiación del espacio y de control sobre el territorio por parte de los europeos que aún no se ha completado, a pesar de la conquista formal de la provincia concluida varias décadas antes.

En esta fase temprana de colonización, otro ejemplo que refuerza la apropiación aún débil del territorio por parte de los españoles es la mención, en el texto de la Relación, de uno de los primeros episodios de incursión corsaria en la provincia:

Habrá 8 o 9 años [es decir 1570-1571] estuvo en este rio [Dos Bocas] un navío de ingleses corsarios, de donde quisieron prender a un soldado que acaso venía de la ciudad de la Veracruz, el cual conociéndoles se apartó y fue de ellos; los cuales escribieron de allí una carta para un Roberto que estaba en la México; [...], la cual [carta] trajeron a esta villa [Santa María de la Victoria] dos hombres de la mar que ellos tenían consigo y les habían preso en el río de Puerto Escondido [en la laguna de Términos] de la provincia de Yucatán, [...] estaban sondeando los puertos de esta costa y tomando agua y leña... cuando estos corsarios estuvieron sobre este rio sondándole, esta villa estuvo en mucho aprieto, así por el trabajo que se tenía en la guarda y custodia de esta villa en la ordinaria de la costa y playa, demás de verse sin ninguna fuerza para se poder resistir, por no tener como no tienen siquiera una pieza para hacer alguna apariencia de guerra a los enemigos. ${ }^{36}$

Es interesante aquí notar la declaración de falta de infraestructura de defensa en la costa y las dificultades en proteger la villa de Tabasco de ataques extranjeros. Como argumenta Francisco Jiménez Abollado, el débil control del territorio por parte de las autoridades coloniales se debe a varios factores, todos relacionados con la condición de marginalidad y zona de frontera de la provincia; por ejemplo, los bajos índices de población española e indígena, la lejanía de los centros de poder, y los frecuentes cambios jurisdiccionales, entre otros. ${ }^{37}$ Estos problemas internos facilitaron los ataques corsarios y la presencia de cortadores ilegales de palo de tinte en la laguna de Términos desde las primeras décadas de la Colonia. En términos de poder de movilidad, este panorama permitía que actores extranjeros, enemigos de la Corona española, tuvieran libre acceso a la región, y por

${ }^{36}$ De la Garza et al., Relaciones histórico-geográficas, 45.

37 Jiménez Abollado, Entre ríos, pos. 510. 
ende, un conocimiento y aprovechamiento mayor que los legítimos ocupantes del territorio.

Actores que, en cambio, tenían una libertad de movimiento "legítima" en el territorio colonial eran los frailes misioneros. En la historia eclesiástica colonial de México, Tabasco siempre ha tenido un papel marginal en la actividad evangelizadora, probablemente por su cualidad de zona de frontera, alejada geográficamente del centro de México y de las ciudades importantes en el sureste como Mérida y Ciudad Real. ${ }^{38}$ Jiménez menciona cómo la actividad evangelizadora en Tabasco sufrió por las condiciones físicas del territorio, las dificultades de moverse, junto a la escasa población indígena, a la que debía adoctrinar, y de población española a la cual apoyar. ${ }^{39}$ Debido a esta marginalidad, la provincia de Tabasco vivió una serie de cambios jurisdiccionales de carácter político y eclesiástico, entre las entidades de Chiapas y Yucatán, cambios que afectaron el establecimiento de doctrinas y visitas por las órdenes religiosas. ${ }^{40}$

Hay pocos documentos acerca de viajes misioneros en Tabasco. En general, lo que se percibe de estas fuentes es la imposibilidad de llevar a cabo la obra evangelizadora en Tabasco por su territorio fragmentado, cruzado por ríos y por la oposición de los encomenderos y las autoridades locales, que encontraban en los frailes unos fieros opositores a sus prácticas de abusos y maltratos hacia los naturales. ${ }^{41}$

Uno de los primeros testimonios sobre esta actividad evangelizadora, en las primeras décadas del periodo colonial, es el diario del fraile dominico Tomás de la Torre. El diario describe el viaje que el fraile emprendió entre 1544-1545 para acompañar al nuevo obispo de Chiapas, fray Bartolomé de las Casas, en su viaje desde España a Ciudad Real. ${ }^{42}$ El texto, no sólo proporciona una descripción temprana y muy detallada de las condiciones sociales y geográficas de Tabasco, también ofrece diferentes

${ }^{38}$ Ruz, Un rostro encubierto; Francisco Jiménez Abollado, "Los cambios jurisdiccionales eclesiásticos en la provincia de Tabasco durante el siglo XVI y principio del XVII", Estudios de Historia Novohispana, v. 36 (2007): 83-99, DoI: 10.22201/iih.24486922e.2007.036.3660.

39 Jiménez Abollado, "Los cambios jurisdiccionales”, 83-86.

${ }^{40}$ Jiménez Abollado, "Los cambios jurisdiccionales”, 83-86.

${ }^{41}$ Francisco Morales Valerio, "Fray Jacobo da Tastera (1490?-1542). Un notable misionero en Tabasco", Arqueología Mexicana, v. XI, n. 61 (2003): 58-61. Al mismo tiempo hay reportes de vejaciones y abusos por parte de las mismas autoridades eclesiásticas en la provincia, véanse los casos reportados por M. Humberto Ruz, Un rostro encubierto, 139-142.

${ }^{42}$ Fray Tomás de la Torre, Desde Salamanca, España, hasta Ciudad Real, Chiapas. Diario del viaje 1544-1545, pról. y notas de Franz Blom (México: Gobierno Constitucional del Estado de Chiapas, 1974); Cabrera Bernat, Viajeros en Tabasco, 163-236. 
elementos sobre la organización y las políticas de la movilidad. En la sección del diario relativa a la llegada a las costas de la Nueva España, el fraile describe las rutas, la infraestructura y el sistema de movilidad entre la costa y el interior de Tabasco a través de sus ríos.

Al principio de esta sección, que describe la navegación en el mar Caribe desde la isla de La Española hasta Campeche, encontramos lo que probablemente es uno de los primeros testimonios de la presencia de piratas en el golfo de México: "Íbamos con gran miedo de franceses y así de día nos metíamos en alta mar y de noche nos acercábamos a tierra con temor siempre de franceses... [...] que ni llevábamos tiros, ni armas, ni defensa alguna..."43

Este pasaje deja entrever la falta de protección con la que viajaba la mayoría de las embarcaciones españolas de pasajeros en el golfo de México. Llegando a la costa de Campeche, el texto ofrece una interesante descripción de las embarcaciones, que muestra un uso de medios de transporte mixtos de origen local (canoas) y europeo (bateles) para ayudar a los religiosos a desembarcar. El viaje es complicado y trágico, marcado por un naufragio y muerte de algunos de los frailes en la laguna de Términos. Varios pasajes describen la organización del transporte en esta región, basada sobre todo en canoas, y en la tecnología de navegación de los mayas chontales. De nuevo, como en las cartas de Cortés, un tema que se repite es la falta de caminos establecidos por vía terrestre y la necesidad de moverse en canoa, mencionando que los guías indígenas sólo saben los caminos por agua, "llevar por tierra decían que no podía ser por las grandes ciénegas y lagunas que hay..." ${ }^{4}$

Fray Tomás describe el uso mixto de barcos (algunas aparentemente con cubierta) de estilo europeo que navegan a lo largo de la costa, así como de canoas manejadas por indígenas, e incluye la presencia de infraestructura en apoyo a la navegación, ya que navegando a lo largo de la costa entre la laguna de Términos y la desembocadura del Grijalva, el fraile menciona "una lumbre" que ayudó al piloto a entrar en el río.

El domingo de mañana amaneció buen tiempo, y el señor obispo se fue en la barca [...] Aquel día tuvieron calma, y á la tarde tuvieron tan bravo norte que pensaron perderse y los que quedamos en la isleta les tuvimos gran temor. Quisieron meterse en la boca de un gran rio que llaman San Pedro y San Pablo pero no quiso el

${ }^{43}$ Cabrera Bernat, Viajeros en Tabasco, 168.

${ }^{44}$ Cabrera Bernat, Viajeros en Tabasco, 184. 
arraes o piloto porque era de noche y no sabía aquel rio, y asi fueron sin saber dónde; $[. .$.$] y el viento parecía hacer pedazos la barca que por ir mal cargada corría$ más peligro. En esto se les apareció o descubrió en tierra una lumbre con que conocieron que estaban cerca del rio de Tabasco y que entraban por él $[\ldots] .{ }^{45}$

Otra mención de apoyo a la navegación en este sector de la región costera fue documentada por el obispo de Yucatán Diego de Landa. En su viaje para tomar posesión de su cargo en Yucatán, entre 1575 y 1576, se queda varios meses en Tabasco, y describe la presencia de señales en los árboles para guiar el tráfico en el enredo de vías acuáticas entre Tabasco y Campeche. ${ }^{46}$

Desde la Villa de Tabasco, el viaje de fray Tomás y sus compañeros sigue por río a lo largo del Grijalva, gracias a la generosidad de algunos vecinos que "donan" unas canoas a los frailes. A este propósito sería interesante aclarar si las canoas son de los vecinos españoles o si ellos simplemente "prestan" el trabajo de los indígenas que tienen encomendados para acompañar y guiar a los frailes.

Tacotalpa representa el término de la navegación y el camino de los frailes continuará ahora vía terrestre, subiendo la sierra Zoque entre Tabasco y Chiapas, y siguiendo luego hasta Ciudad Real. El camino se vuelve difícil, por el clima y las cuestas que deben subir y los ríos que deben atravesar, a pie o cargados por los guías indígenas. Al respecto, menciona el fraile que algunos de los religiosos, muy afectados por el viaje, son transportados en "hamacas [que] usan ellos para llevar a sus señores y principales y a los enfermos y en estas andan ahora las mujeres de Castilla que van en camino y aun los españoles se hacen llevar en estas cuando van a sus pueblos, especialmente cuando es mal camino por donde no pueden ir a caballo..." 47

El largo y difícil viaje emprendido por fray Tomás de la Torre y sus compañeros deja vislumbrar varios aspectos interesantes acerca de la organización de la circulación en las primeras décadas de la Colonia, que se refiere tanto a los medios de transporte y a la infraestructura, así como a las prácticas de movilidad.

Por ejemplo, en la descripción de las embarcaciones por parte de los frailes, se distingue una gran variedad, como barcas, bateles y canoas, es decir una tecnología mixta de tradición europea e indígena. Refiriéndose a

${ }^{45}$ Cabrera Bernat, Viajeros en Tabasco, 197-198.

46 Tozzer 1941:5, cit. en Lee, “The Historical Routes”, 61.

${ }^{47}$ Cabrera Bernat, Viajeros en Tabasco, 219. 
un segundo grupo de frailes que se había demorado en Xicalango para recuperar lo salvable del naufragio, fray Tomás dice que el grupo retoma el camino hacia la villa de Tabasco "Vía mar donde tenían canoas para ir a Tabasco por la mar [...] aquella tarde entráronse en las canoas y entráronse bien dentro la mar [...] después vino un bravísimo norte y volviendo las espaldas tomáronlo en popa porque las canoas llevaban velas y salieron en tierra. ${ }^{48}$

Esta mención de canoas con velas es de lo más sugerente: por un lado, podría tratarse de una mala interpretación, por parte del fraile, de una embarcación de estilo europeo; por el otro, podría hacer referencia a una técnica mixta, que adapta el uso de velas a una canoa indígena. ${ }^{49}$

Aunque en varios pasajes del texto el fraile mencione la presencia de personajes a caballo, que se ofrecen a ayudarlos, éstos son escasos y su uso es limitado a colonos españoles; ${ }^{50}$ por lo general, la movilidad presupone transporte acuático o a pie. Esto habla de un territorio aún no completamente adaptado a la movilidad europea, ya que en estas primeras décadas de la Colonia, los caminos por la vía terrestre siguen siendo escasos, y por ende, los españoles se apoyan casi totalmente en el sistema de transporte indígena.

Una situación similar es descrita para las provincias de Tlacotalpan y Coatzacoalcos, en Veracruz, por Mariana Favila. La autora, reportando una descripción de Motolinía, menciona que el principal medio de comunicación entre los pueblos era la canoa, y que "estas barcas o acales salen a recibir y llevar a los frailes de un pueblo al otro". ${ }^{51}$ Es muy probable que las canoas descritas por fray Tomás de la Torre sean el mismo tipo de "acalli" (término que significa literalmente "casa sobre agua” en náhuatl) es decir, embarcaciones monóxilas, ${ }^{52}$ descritas por Motolinía.

Un último aspecto importante en referencia al sistema de movilidad para la primera época colonial es la escasa presencia de infraestructura de vigías y control de las costas. Aparte de algunas formas rudimentarias de

${ }^{48}$ Cabrera Bernat, Viajeros en Tabasco, 212-213.

49 Agradezco a la doctora Mariana Favila por sugerir la posibilidad de una canoa indígena con vela (comunicación personal, 9 de noviembre 2020).

${ }^{50}$ A este propósito es interesante mencionar que unas décadas después las autoridades coloniales obligaban a los nobles indígenas a comprar cédulas para montar a caballo, $c f r$. Ruz, Un rostro encubierto, 115.

${ }^{51}$ Fray Toribio de Benavente, 1971:227, cit. en Mariana Favila, Veredas de mar y río. Navegación prehispánica y colonial en Los Tuxtlas, Veracruz, Colección Posgrado (México: Universidad Nacional Autónoma de México, Coordinación de Estudios de Posgrado, 2016), 200-201.

52 Canoa fabricada de una sola pieza de madera. 
vigías y señalación para la navegación, lo que emerge de las fuentes es una infraestructura limitada para finales del siglo Xvi y buena parte del siglo XVII. La costa de Tabasco no solamente es abandonada a nivel demográfico, sino también descuidada a nivel de defensa. Este desinterés hará que desde finales del siglo XVI, la región costera de Tabasco sea víctima de numerosos ataques de piratas y corsarios europeos. Estos personajes, al contrario, construyen infraestructura de transporte y vigilancia en la laguna de Términos, para llevar a cabo intereses comerciales propios y de gobiernos europeos enemigos de la Corona española.

A este propósito, es iluminante el testimonio del pirata inglés William Dampier que, para finales del siglo XVII, describe las instalaciones de los cortadores de palo de tinte ilegalmente establecidos en la laguna. Estas infraestructuras incluyen un fuerte, varias cabañas, parapetos de defensa, además de embarcaciones y artillería. ${ }^{53}$ Sólo a finales del siglo Xviı se contará con un esfuerzo real por parte del gobierno virreinal para alejar a los corsarios y cortadores de tinte de las costas de Tabasco-Campeche. Esto se une a una nueva política de movilidad, donde se refleja una mayor capitalización del territorio costero, a través de la construcción de vigías, instituciones de impuestos para mantener guardias a lo largo de la costa y la constitución, en 1635, de la armada de Barlovento, para limitar la libre movilidad de los corsarios y proteger el comercio de la Corona. ${ }^{54}$

Este desinterés hacia la costa y la evidente predilección por una estrategia tierra adentro en el sistema de movilidad que se vislumbra en las fuentes del siglo XVI, emerge también en las prácticas y narrativas de movilidad, y en los mapas contemporáneos, donde el interés parece enfocado hacia la consolidación de un territorio interno, mientras que la red costera de ríos y lagunas es abandonada.

Prácticas de movilidad, prácticas de resistencia

El movimiento vivido y practicado a través del cuerpo constituye el segundo elemento de las políticas de movilidad. ${ }^{55}$ El acceso diferencial al movimiento, las razones voluntarias u obligadas por las cuales la gente se mueve,

${ }^{53}$ Cabrera Bernat, Viajeros en Tabasco, 235-276.

${ }^{54}$ Véase para este propósito, María Ángeles Eugenio Martínez, La defensa de Tabasco, 1600-1717 (México: Gobierno del Estado de Tabasco, Consejo Editorial, 1988).

55 Cresswell, "Towards a Politics", 20. 
dejan rastro en la organización social y política. Ya se ha mencionado cómo a través de las encomiendas y las reducciones, el dominio colonial pudo controlar y limitar el libre movimiento de los indígenas. Al mismo tiempo, las fuentes documentales a menudo dejan ver ejemplos de prácticas y experiencia de movimiento de diferentes actores, y cómo estas prácticas responden, se adaptan, fomentan, o se oponen a las relaciones de poder establecidas. Un claro ejemplo de resistencia a las formas de inmovilidad o movilidad forzosa impuesta por la Corona es la "huida" a la montaña por parte de los grupos indígenas del sureste para evitar ser obligados a vivir en los pueblos reducidos y escapar al yugo de la encomienda y del repartimiento forzoso de mercancías. Esta práctica, que en los primeros encuentros entre europeos e indígenas parece una táctica para evitar momentáneamente el apoyo a los españoles en sus actividades de conquista, ${ }^{56}$ se vuelve luego una estrategia de sobrevivencia con la formación de pueblos de huidos, que por décadas logran sustraerse del yugo colonial. Para Tabasco, un ejemplo de este fenómeno es la sublevación de varios pueblos en el Partido de los Ríos, en la segunda mitad del siglo XVII, los cuales para escapar de las vejaciones de las autoridades provinciales, sobre todo la práctica de los repartimientos forzosos, y de los frecuentes ataques por parte de los piratas de la laguna de Términos, abandonan sus asentamientos, con el apoyo de los indios insumisos "del monte", y logran instalarse - temporalmente- en territorios libres. ${ }^{57}$

En este sentido, el testimonio de Dampier, que entre 1675 y 1688 vive y trabaja con piratas y cortadores de palo de tinte en la laguna de Términos, lugar que se había vuelto la base de operaciones de contrabando de esta fuente de colorante muy apreciada en Europa, deja entrever prácticas de movilidad mucho más fluidas de lo que aparentan las fuentes oficiales. En el texto, Dampier describe un lugar que llama Beef Island, donde él y otros cortadores iban a cazar. Este lugar — de acuerdo con la descripción- corresponde a la península de Xicalango, al oeste de la laguna de Términos. Aquí, según el pirata, hay árboles frutales que, dice, "fueron recientemente

${ }^{56}$ Cortés, Cartas de relación, 225-226.

${ }^{57}$ Francisco Jiménez Abollado, "Rebelión en el Partido de los Ríos, 1668-1671", en M. Humberto Ruz, ed., Tabasco: antiguas letras, nuevas voces (Mérida: Universidad Nacional Autónoma de México, 2005), 117-139; véase también, Pedro Bracamonte y Sosa, La conquista inconclusa de Yucatán. Los mayas de la montaña 1560-1680 (México: Centro de Investigaciones y Estudios Superiores en Antropología Social, 2001). 
plantados por una colonia de indios que se sublevaron contra los españoles y se establecieron aquí". ${ }^{58}$ En el pasaje siguiente continúa:

...No es novedad entre los indios de estas regiones madereras de América que emigren pueblos completos a la vez y que se establezcan en las selvas poco frecuentadas para gozar de libertad, y si accidentalmente fueran descubiertos se mudarán de nueva cuenta [...ya que...] la selva les asegura alguna subsistencia [...] Habían estado aquí [en la isla] durante casi un año antes de que fueran descubiertos por los ingleses. ${ }^{59}$

El pirata menciona también que los indígenas "Tienen caminos a los plantíos que nadie conoce sino ellos", ${ }^{60}$ y que "no hacen veredas, pero dejan marca a lo largo del camino". ${ }^{61}$ Además, afirma que, si son "descubiertos por otros indígenas que todavía viven entre los españoles, o desconfían de ellos, inmediatamente llevan sus viviendas a otro lado". ${ }^{62}$ Estas anécdotas nos hacen entrever las fallas en el control de este territorio por parte de las autoridades españolas, y - al mismo tiempo- nos hablan de las prácticas de resistencia de indígenas y piratas.

Otra práctica importante en el marco de las políticas de movilidad concierne a las formas de movilidad forzosa. Un ejemplo interesante es la figura de los indios remeros y cargadores que aparece en varios documentos. Para el periodo prehispánico, el cargador o tlameme es una figura conocida, sobre todo en relación con los mercaderes mexicas y mayas del periodo posclásico. El papel de los "indios remeros" o "cargadores" en los albores de la Colonia, cuando aún los animales de carga no eran abundantes, o en áreas donde ir a caballo no era viable, como por ejemplo en las zonas pantanosas y de selva del sureste, merece un estudio más atento.

Un ejemplo interesante sobre estos personajes y sus prácticas de navegación, lo encontramos nuevamente en el diario de fray Tomás de la Torre. En su narración del traslado en la laguna de Términos, el fraile menciona caravanas de canoas, atadas de dos en dos para mantener una navegación conjunta y evitar peligros; en varios momentos del viaje los remeros tenían que jalar las canoas por el bajo nivel del agua. ${ }^{63}$

${ }^{58}$ Cabrera Bernat, Viajeros en Tabasco, 251.
${ }^{59}$ Cabrera Bernat, Viajeros en Tabasco, 252.
${ }^{60}$ Cabrera Bernat, Viajeros en Tabasco, 252.
${ }^{61}$ Cabrera Bernat, Viajeros en Tabasco, 252.
${ }^{62}$ Cabrera Bernat, Viajeros en Tabasco, 252.
${ }^{63}$ Cabrera Bernat, Viajeros en Tabasco, 208. 
Una vez llegados a la villa de Tabasco, algunos compañeros de fray Tomás son ayudados en el viaje por Francisco Gil, un vecino español que "tenía su casa y hacienda en el cabo de aquel rio, o por mejor decir en el principio y hallose aquí [en la Villa de Tabasco] a la sazón con canoas y aunque la tenía para otra cosa, dejola y llevó consigo a los religiosos”. ${ }^{64}$

Otro grupo de frailes recibe "en dono" por parte de algunos vecinos de la villa unas canoas (con los canoeros) para seguir su viaje hacia Chiapas, sin aclarar cuál será la suerte de estos indígenas una vez que los frailes lleguen al fin de la navegación. Un pasaje interesante, que deja entrever una posible práctica de resistencia a esta forma de trabajo, es la mención durante la navegación a lo largo del río Grijalva del mismo grupo de frailes de una canoa que cambia de rumbo metiéndose en otro brazo del río: "Hízoles entender Francisco Gil que uno de los ríos [el Teapa] que habían visto entrar a aquel rio [el río de la Sierra o Tacotalpa donde iban] iba a dar al pueblo de a donde eran aquellos indios remeros y que solo Dios bastara para hacerles ir sino por el camino de su pueblo y que después habían de pasar todos por él y allí hallarían a aquellos padres..." ${ }^{65}$

Este fragmento parece aludir al hecho de que no siempre el trabajo de remero fuera voluntario y que en ocasiones los indígenas, forzados a llevar a cabo esta actividad, trataran de regresar a su pueblo.

El mismo texto del fraile, así como un pasaje de la Relación histórico-geográfica de la Villa de la Victoria mencionan que estos indios remeros proceden de localidades específicas de Tabasco, es decir, de los pueblos de Tlacotalpa y Teapa, en la sierra, y de la región de Chiltepec. ${ }^{66}$

Otra referencia, esta vez de la región de los Ríos, es presentada por Jan De Vos en su texto sobre fray Pedro Lorenzo, fundador del pueblo de Palenque y misionero en Chiapas y Tabasco. ${ }^{67}$ Figura mal vista por las autoridades dominicas de Chiapas, por su libertad de movimiento e independencia, fray Pedro participa, con Feliciano Bravo, escribano oficial de Yucatán, alrededor de 1580, en dos expediciones a la tierra de los itzaes, pueblo insumiso del

${ }^{64}$ Cabrera Bernat, Viajeros en Tabasco, 208.

${ }^{65}$ Los frailes iban navegando río arriba en el río la Sierra o Tacotalpa, mientras que el segundo grupo se adentró en un brazo de éste, el río de Teapa, Cabrera Bernat, Viajeros en Tabasco, 214.

${ }^{66}$ De la Garza et al., Relaciones histórico-geográficas, 46.

${ }^{67}$ Jan De Vos, Fray Pedro Lorenzo de la Nada. Misionero de Chiapas y Tabasco (México: Fondo de Cultura Económica; México: Centro de Investigaciones y Estudios Superiores en Antropología Social, 2010). 
Petén guatemalteco, para convencer a estas poblaciones a salir de la selva y aceptar vivir en pueblos reducidos. Para las dos expediciones - sin éxito- en que el fraile se embarca se sirve del apoyo de indios remeros de las poblaciones del Usumacinta, los cuales forman la frontera cristiana con las tierras de guerra de El Petén. Al parecer, las expediciones fracasan no solamente por la escasez de víveres y por haber caído enfermo fray Pedro, sino también por la negativa de los guías remeros de seguir prestando sus servicios y ausentarse más tiempo de sus pueblos. ${ }^{68}$ Es interesante subrayar que en la relación escrita por fray Pedro, e incluida en el texto de Jan De Vos, se insiste en el justo pago y horas de descanso que los indios, guías y remeros, de la expedición recibieron.

Es evidente que a pesar de que la actividad de guía y remero en teoría implicara un salario, en la práctica se convierte, en muchos casos, en trabajo forzoso. La práctica se vuelve tan frecuente que las autoridades tienen que intervenir oficialmente para evitar tales abusos. En 1591, encontramos una orden del virrey al alcalde mayor de Tabasco en donde se prohíbe forzar a los nativos de los pueblos de Tabasco a trabajar como canoeros contra su voluntad para cargar mercancías y mercaderes de los españoles, prohibiendo que remen por 24 horas al día, y ordenando que se les pague un salario justo. ${ }^{69}$

En conclusión, aunque el empleo de tamemes y canoeros para transportar mercancía y viajeros remontaba al periodo prehispánico, en la Colonia esta práctica parece volverse más explotadora, ya que los españoles "se hacen llevar en estas [hamacas] cuando van a sus pueblos, especialmente cuando es mal camino por donde no pueden ir a caballo". ${ }^{70}$ Además de recurrir a las vías legales, como se ve en la orden del virrey arriba mencionada, otras prácticas de resistencia para enfrentar estos abusos es la ya mencionada "huida" a las montañas.

${ }^{68}$ Documento 5. Relación que hace fray Pedro Lorenzo de su entrada a El Petén en 1580. Palenque, 26-IV-1580 (AgI, México 109) fragmento incluido en Jan De Vos, Fray Pedro Lorenzo, $75-77$.

${ }^{69}$ Documento 6. "Mandamiento del Virrey al Alcalde Mayor de la villa de Tabasco, para que no consienta que los indios de Cauatlán y Astapa sean compelidos a dar, contra su voluntad, canoas y remeros. 14 de octubre de 1591" (AGN, Indios v. 5, exp. 942) incluido en Ruz, Un rostro encubierto, 302-303.

${ }^{70}$ De la Torre, Diario, 152-153. 
Representaciones de la movilidad: el mapa de la provincia de Tabasco de Melchor de Alfaro Santa Cruz

La tercera esfera en que se refleja una determinada política de movilidad concierne a las representaciones y narrativas creadas alrededor del movimiento. En este sentido, los mapas representan objetos clave para entender los discursos de control sobre un territorio, y, por ende, sobre el movimiento. El acto de nombrar, representar y clasificar el espacio en un mapa transforma este espacio en un objeto que se puede comprender y colonizar. Por esta razón, los mapas son implicados directamente en la creación de la realidad que presumen revelar. ${ }^{71}$

En el primer siglo de la historia novohispana de México, como en otros contextos de imperios coloniales emergentes, la producción de mapas era una herramienta eficaz en las manos de la autoridad para materializar su control real e "imaginario" sobre los territorios ultramarinos. Una de las primeras manifestaciones de este control son los mapas que acompañan las ya mencionadas Relaciones histórico-geográficas. ${ }^{72}$ Entre los mapas que han sobrevivido, los estudiosos reconocen "pinturas" de autores españoles, que siguen la tradición europea, "pinturas” de autores indígenas, más cercanas a la tradición pictórica indígena, y formas "mixtas", aunque en casi todas se pueden reconocer influencias recíprocas. ${ }^{73}$

El mapa que acompaña la Relación de Tabasco pertenece al primer grupo. ${ }^{74}$ La imagen es contenida en un marco circular, forma que comparte con algunas otras pinturas de estos documentos. ${ }^{75} \mathrm{El}$ mapa de Tabasco, que lleva

${ }^{71}$ Craib, "Cartography”, 10-13.

${ }^{72}$ Para una discusión sobre el origen y los propósitos de los mapas que acompañan las Relaciones histórico-geográficas, véase Barbara Mundy, The Mapping of New Spain (Chicago: The University of Chicago Press, 1996); Carmen Manso Porto, "Los mapas de las Relaciones geográficas de Indias de la Real Academia de la Historia”, Revista de Estudios Colombinos, n. 8 (junio 2012): 23-52; Enrique Delgado López, "Paisaje y cartografía en la Nueva España. Análisis de dos mapas que acompañan al corpus de las Relaciones geográficas (1577-1583)", Estudios de Historia Novohispana, v. 28 (2003): 77-102.

${ }^{73}$ Mundy, The Mapping.

${ }^{74}$ Para un estudio detallado sobre el mapa de Tabasco y su autor, véase Flora Salazar Ledesma, Figura de una tierra, de la forma y manera según que está (Villahermosa: Instituto Nacional de Antropología e Historia de Tabasco, 2010).

${ }^{75}$ Para un análisis de los mapas circulares de las Relaciones histórico-geográficas, véase Delgado López, "Paisaje y cartografía”; Alessandra Russo, El realismo circular. Tierras, espacios y paisajes de la cartografía indígena novohispana, siglos XVI y XVII (México: Universidad Nacional Autónoma de México, Instituto de Investigaciones Estéticas, 2005); Salazar Ledesma, Figura de una tierra. 
la fecha del 26 de abril de 1579, es uno de los pocos de los cuales se conoce el autor, el encomendero Melchor de Alfaro Santa Cruz, aunque hay opiniones contrastantes sobre si el autor trabajó solo, ayudado por un cartógrafo indígena o si se apoyó en un mapa local preexistente. ${ }^{76}$ Los cuatro lados del mapa están marcados con los puntos cardinales, y aunque la pintura parece orientada al este, la mayoría de los textos contenidos en los numerosos cartuchos, así como el título, se leen poniendo el sur arriba. Este aspecto ha llevado a varios estudiosos a proponer una lectura multiorientada de estos mapas circulares, que presupone una visión a 360 grados hacia el horizonte y una predisposición hacia el movimiento y rumbos direccionales. ${ }^{77}$ Flora Salazar, estudiosa del mapa, argumenta que "en la pintura de Alfaro Santa Cruz hay entonces una combinación entre los sentidos de ubicación, de dirección fija y de rumbo y así están plasmados en la circularidad de la imagen". ${ }^{78}$

En general, en la imagen destacan la orografía y la hidrografía de la provincia, con particular referencia a la ubicación de pueblos, encomiendas, estancias de ganados, cultivos de cacao, vías de comunicación, serranías y ríos. Las anotaciones nombran y describen los elementos del paisaje, con información acerca de la distancia entre los pueblos y la navegabilidad de los ríos.

En términos de sistema de movilidad, el aspecto más sobresaliente del mapa es la representación de la red de cuerpos de agua y de líneas oscuras que indican las rutas terrestres que unen a los pueblos. Hacia 1579, como se ha mencionado antes, la provincia de Tabasco cuenta con una red de caminos implementada por los españoles que conectan los asentamientos, las encomiendas y las principales estancias ganaderas y cacaoteras (véase el mapa 2). Según las anotaciones en el mapa, parece que la red hidrográfica sigue siendo la mayor arteria de comunicación para los indígenas, aunque, las mismas anotaciones dejan entrever que esta red de comunicación fluvial-lagunar-costera está lejos de ser aprovechada en su totalidad por los españoles.

A pesar de la gran dinámica hidrogeológica que ha caracterizado Tabasco desde la Colonia hasta el presente, Salazar ha podido identificar la mayoría de las corrientes fluviales con ríos actuales. ${ }^{79}$ Emerge en la pintura el

${ }^{76}$ Salazar Ledesma, Figura de una tierra, 19-21.

77 Salazar Ledesma, Figura de una tierra, 19-21; Delgado, "Paisaje y cartografía”, 90.

${ }^{78}$ Salazar Ledesma, Figura de una tierra..., 89.

${ }^{79}$ Flora Salazar Ledesma, "Rasgos significativos de la hidrografía y del proceso de poblamiento español de la cuenca baja del Mazapa en Tabasco en 1579”, en Los Investigadores de la Cultura Maya 12, t. II (Campeche: Universidad Autónoma de Campeche, 2004), 400-416. 
lugar central que ocupan los ríos Grijalva y Mazapa, y su importancia como ejes articuladores de movilidad. Por ejemplo, en referencia a la navegación a lo largo del Grijalva, una de las anotaciones dice "Por este rio desde el primer pueblo de la sierra hasta la villa de Tabasco hay treinta leguas". 80

A pesar de estas informaciones detalladas, varios autores han señalado la orientación imprecisa de varios sectores del mapa, por ejemplo la región de la Sierra, que aparece al este en lugar de estar al sur. ${ }^{81}$ En relación con este último punto, Salazar propone que el autor, más que demostrar un interés en la ubicación exacta de algunas áreas, prefiere indicar la dirección a tomar para alcanzar dichos lugares, ${ }^{82}$ creando - en mi opinión - un mapa que presupone el movimiento a lo largo del territorio. La idea de un espacio vívido hecho para moverse y ser conocido a través de la movilidad, terrestre y fluvial, emerge también de las numerosas anotaciones que ofrecen informaciones acerca de distancias, rumbos y medios para moverse en este paisaje. Por ejemplo, acerca del pueblo de Tamulté, ubicado en el sector central de la provincia, se lee: "Hay de aquí a la villa [de Tabasco] doce leguas, van por río no hay camino". Esta expresión "van" por río me parece de lo más interesante. El autor pasa de la forma impersonal típica de otras anotaciones al "van", refiriéndose a terceros ¿Serán estos "ellos” los indígenas que se mueven prevalentemente por agua, para diferenciarlos de los españoles?

Otro aspecto que podría indicar, desde la perspectiva de los españoles, un proceso de apropiación del espacio y un control sobre la movilidad que aún no se ha completado son los numerosos comentarios del autor acerca de la dificultad de trasladarse en la región. Por ejemplo, al lado del cartucho que indica el norte, donde está ubicada la villa de Tabasco, hay una anotación que dice "todo esto aquí adentro es de tierra de grandes ciénegas y anegadizo, no se puede andar" (véase el mapa 3). Este sector representa una zona inundable, caracterizada por el delta de los ríos Grijalva y Usumacinta, donde el comentario "no se puede andar" podría reflejar una práctica española, la de moverse vía terrestre, a pie o a caballo, y no de las

${ }^{80}$ La transcripción de las anotaciones del mapa de Melchor de Alfaro Santa Cruz es reportada en el texto paleográfico de las relaciones histórico-geográficas, en De la Garza et al., Relaciones histórico-geográficas.

${ }^{81}$ Salazar Ledesma, Figura de una tierra; Ana Luisa Izquierdo y Gerardo Bustos, "La visión geográfica de la Chontalpa en el siglo xvi”, Estudios de Cultura Maya, v. 15 (1984): 143-177, DOI: 10.19130/iifl.ecm.1984.15.569.

82 Salazar Ledesma, Figura de una tierra, 84. 
poblaciones indígenas, las cuales desde siempre se han trasladado con canoas, conociendo ríos, canales y lagunas de la franja costera.

Estos elementos del mapa revelan un enfoque hacia el interior y hacia la zona central de la provincia, es decir, la región de la Chontalpa, económica y demográficamente más importante ${ }^{83}$ mientras que las áreas costeras y serranas quedan al margen de la descripción, y - probablemente-del control sobre el territorio. La costa de Tabasco aparece más como un límite que como un conector de movimiento, como en cambio lo había sido en la época prehispánica a través de la navegación fluvial-costera.

Lo que emerge, en fin, de esta representación es un control de la movilidad más imaginario que real por parte de las autoridades españolas. Este progresivo abandono y desinterés del poder colonial hacia la costa provocará que para finales del siglo XVI varios sectores de la costa, sobre todo de la laguna de Términos, quedarán en manos de corsarios y piratas europeos, situación que agudizará la condición de marginalidad geográfica y económica de la provincia de Tabasco.

Solamente en el siglo XVIII, gracias a un cambio de gobierno, legislaciones y prácticas, se logrará retomar posesión de esta región costera y desalojar a los extranjeros, ${ }^{84}$ proceso que consecuentemente involucrará nuevas infraestructuras, prácticas y narrativas, es decir, una nueva política de movilidad.

\section{Conclusiones}

A través del análisis de documentos oficiales, mapas y otras fuentes, esta investigación ha tratado de presentar la importancia de la organización de la movilidad en los territorios recién colonizados del Tabasco novohispano. La información acerca de la infraestructura, medios de transporte, experiencias individuales y colectivas, así como de las representaciones y narrativas acerca del movimiento, revelan la movilidad como un conjunto de prácticas arraigadas en las relaciones sociales y políticas. Las políticas de movilidad enfocadas al control, reducción, y promoción de la circulación en la región

${ }^{83}$ Una consideración similar ha sido propuesta por Flora Salazar Ledesma, argumentado que Alfaro Santa Cruz, dueño de encomiendas y estancias en la Chontalpa, tenía más interés en describir esta área productiva de la provincia, $c f r$. Salazar Ledesma, Figura de una tierra, 82-83.

${ }^{84}$ Véase para este propósito, Eugenio Martínez, La defensa. 
de Tabasco en los siglos XVI y XVII, dejan entrever un discurso de poder por parte de las autoridades que no siempre coincide con las prácticas sociales registradas en otras fuentes. Al contrastar todas estas fuentes, surge un paisaje político más fluido, donde si las zonas del centro y sur de Tabasco aparecen bajo un dominio colonial más estable, las áreas costeras del norte y de selva al sureste constituyen todavía una zona de frontera porosa, con grupos insumisos, que dejan un amplio margen para prácticas de resistencia. Si los informes y la cartografía de los órganos de gobierno quieren reflejar el control (en parte real y en parte imaginario) sobre el territorio de Tabasco, otros testimonios no oficiales pintan una realidad más matizada acerca de los hábitos y las negociaciones en juego en la organización de la movilidad.

En este sentido, el movimiento, sea éste libre, forzado, limitado o controlado siempre tiene connotaciones políticas y está involucrado en las diferentes facetas de las relaciones de poder. Descifrar las políticas de movilidad existentes en el contexto de la región costera del golfo de México en la primera época colonial puede iluminar procesos históricos de alcance más amplio; por ejemplo, las estrategias de control y legitimación de poder por parte de las autoridades españolas, la existencia de prácticas de resistencia al dominio colonial, así como el papel de los diferentes grupos indígenas, piratas europeos y esclavos africanos, entre otros, en moldear -desde lo que parece una periferia - la nueva realidad de un mundo globalmente interconectado. Entender la movilidad a través de su organización física, experiencias y representaciones, puede, en fin, revelarse como una herramienta novedosa en el estudio de la historia social novohispana.

\section{Agradecimientos}

Esta investigación ha sido posible gracias a una beca posdoctoral otorgada por la Coordinación de Humanidades de la UNAm en el año 2020-2021, llevada a cabo en el Instituto de Investigaciones Históricas de la misma universidad. Agradezco a los dos dictaminadores anónimos por sus comentarios y sugerencias. 


\section{FUENTES}

Bracamonte y Sosa, Pedro. La conquista inconclusa de Yucatán. Los mayas de la montaña 1560-1680. México: Centro de Investigaciones y Estudios Superiores en Antropología Social, 2001.

Cabrera Bernat, Ciprián. Viajeros en Tabasco. Textos. Villahermosa: Gobierno del Estado de Tabasco, 1987.

Chávez Gómez, José Manuel. "Waterways, Legal Ways and Ethnic Interactions. The Rios District of Tabasco during the Seventeenth and Eighteenth Centuries", en Negotiations Within Domination. New Spain's Indian Pueblos Confront the Spanish State. Coord. de E. R. Medrano y S. Kellogs. Boulder: University Press of Colorado, 2010, 209-211.

Cortés, Hernán. Cartas de relación. Nota preliminar de Manuel Alcalá, 16a. ed. México: Porrúa, 1992.

Craib, Raymond B. "Cartography and Power in the Conquest and Creation of the New Spain.” Latin American Research Review, v. 35, n. 1 (2000): 16-17.

Crampton, Jeremy W. y Stuart Elden, comp., Space, Knowledge and Power. Foucault and Geography. Aldershot, UK: Ashgate, 2007.

Cresswell, Tim. "Towards a Politics of Mobility." Environment and Planning D: Society and Space, n. 28 (2010): 17-31, DOI:10.1068/d11407

Garza, Mercedes, de la, Ana Luisa Izquierdo y María del Carmen León Cázares, coord. Relaciones histórico-geográficas de la alcaldía mayor de Tabasco. Relación de la Provincia de Tabasco, Relación de la Villa de Santa María de la Victoria. Villahermosa: Representación del Gobierno del Estado de Tabasco en México, 1988.

Delgado López, Enrique. "Paisaje y cartografía en la Nueva España. Análisis de dos mapas que acompañan al corpus de las Relaciones geográficas (1577-1583).” Estudios de Historia Novohispana, v. 28 (2003): 77-102.

Delle, James. "Power and Landscape: Spatial Dynamics in Early-Nineteenth Century Jamaica.” En M. O'Donovan, coord. The Dynamics of Power. Occasional Paper, n. 30, Carbondale: Southern Illinois University, Center for Archaeological Investigations, 2002, 341-361.

De Vos, Jan. Fray Pedro Lorenzo de la Nada. Misionero de Chiapas y Tabasco. México: Fondo de Cultura Económica; México: Centro de Investigaciones y Estudios Superiores en Antropología Social, 2010.

Eugenio Martínez, María Ángeles, La defensa de Tabasco, 1600-1717. Villahermosa: Gobierno del Estado de Tabasco, Consejo Editorial, 1981.

Farriss, Nancy. La sociedad maya bajo el dominio colonial. Artes de México. México: Consejo Nacional para la Cultura y las Artes, Instituto Nacional de Antropología e Historia, 2012. 
Favila Vázquez, Mariana. Veredas de mar y río. Navegación prehispánica y colonial en Los Tuxtlas, Veracruz. Colección Posgrado. México: Universidad Nacional Autónoma de México, Coordinación de Estudios de Posgrado, 2016.

Izquierdo, Ana Luisa, y Gerardo Bustos. "La visión geográfica de la Chontalpa en el siglo xvi." Estudios de Cultura Maya, v. 15 (1984): 143-177, doi:10.19130/ iifl.ecm.1984.15.569.

Jiménez Abollado, Francisco. “Rebelión en el Partido de los Ríos, 1668-1671.” En Mario Humberto Ruz, ed., Tabasco: antiguas letras, nuevas voces. Mérida: Universidad Nacional Autónoma de México, 2005, 117-139.

Jiménez Abollado, Francisco. "Los cambios jurisdiccionales eclesiásticos en la provincia de Tabasco durante el siglo xvi y principios del xviI." Estudios de Historia Novohispana, v. 36 (2007): 83-99, DOI: 10.22201/ iih.24486922e.2007.036.3660.

Jiménez Abollado, Francisco. Entre ríos, pantanos y sierra. Marginalidad y subsistencia en la provincia de Tabasco (1517-1626). Edición Kindle. Sevilla: Universidad de Sevilla, 2015, DOI: 10.12795/9788447221585.

Lee, Thomas A. "The Historical Routes of Tabasco and Northern Chiapas and Their Relationship to Early Cultural Development in Central Chiapas." En Thomas A. Lee y Carlos Navarrete, coords. Mesoamerican Communication Routes and Cultural Contacts. Papers of the New World Archaeological Foundation, n. 40. Provo, Utah: Brigham Young University, New World Archaeological Foundation, 1978.

Manso Porto, Carmen. "Los mapas de las Relaciones geográficas de Indias de la Real Academia de la Historia." Revista de Estudios Colombinos, n. 8 (junio 2012): 23-52.

Miller, Daniel, y Christopher Tilley. "Ideology, Power and Prehistory: An Introduction.” En D. Miller y C. Tilley, coord. Ideology, Power and Prehistory, 1-15. Cambridge: Cambridge University Press, 1984, DOI: 10.1017/CBO9780511 897443.

Morales Valerio, Francisco. "Fray Jacobo da Tastera (1490?-1542). Un notable misionero en Tabasco.” Arqueología Mexicana, v. 11, n. 61 (2003): 58-61.

Mundy, Barbara. The Mapping of New Spain. Chicago: The University of Chicago Press, 1996.

Ortiz, Martín, Los caminos de Tabasco. Las vías de comunicación terrestre y la historia de Tabasco desde la época prehispánica hasta 1850. Villahermosa: Gobierno del Estado de Tabasco, Secretaría de Educación, Cultura y Recreación, 1988.

Pacheco, Vargas, Ernesto, y Lorenzo Ochoa, "Navegantes, viajeros y mercaderes: notas para el estudio de la historia de las rutas fluviales y terrestres entre la costa de Tabasco-Campeche y tierra adentro." Estudios de Cultura Maya, v. 14 (1982): 69-118, DOI: 10.19130/iifl.ecm.1982.14.551. 
Russo, Alessandra. El realismo circular, tierras, espacios y paisajes de la cartografía indígena novohispana, siglos XVI y XVII. México: Universidad Nacional Autónoma de México, Instituto de Investigaciones Estéticas, 2005.

Ruz, Mario Humberto. Un rostro encubierto. Los indios del Tabasco colonial. México: Centro de Investigaciones y Estudios Superiores en Antropología Social; México: Instituto Nacional Indigenista, 1994.

Ruz, Mario Humberto. Los linderos del agua. Francisco de Montejo y los orígenes del Tabasco colonial. Villahermosa: Gobierno del Estado de Tabasco, 1991.

Salazar Ledesma, Flora Leticia. Figura de una tierra, de la forma y manera según que está... Villahermosa: Instituto Nacional de Antropología e Historia-Tabasco, 2010.

Salazar Ledesma, Flora Leticia. "Rasgos significativos de la hidrografía y del proceso de poblamiento español de la cuenca baja del Mazapa en Tabasco en 1579." En Los Investigadores de la Cultura Maya, 12, t. II, 400-416. Campeche: Universidad Autónoma de Campeche, 2004.

Scholes, Frances V., y Ralph L. Roys. Los chontales de Acalan-Tixchel. The Maya Chontal Indians of Acalan-Tixchel. Edición castellana de Mario Humberto Ruz y Rosario Vega. México: Universidad Nacional Autónoma de México, Centro de Estudios Mayas; México: Centro de Investigaciones y Estudios Superiores en Antropología Social, 1996.

Sheller, Mimi, y John Urry, "The New Mobilites Paradigm." Environmental and Planning A, n. 38 (2006): 207-226, DoI: 10.1068/a37268.

Torre, fray Tomás, de la. Desde Salamanca, España, hasta Ciudad Real, Chiapas. Diario del viaje 1544-1545. Pról. y notas de Franz Blom. México: Gobierno Constitucional del Estado de Chiapas, 1974.

Urry, John. Mobilities, Cambridge, uk: Polity Press, 2007.

Vargas Pacheco, Ernesto, y Lorenzo Ochoa. "Navegantes, viajeros y mercaderes: notas para el estudio de la historia de las rutas fluviales y terrestres entre la costa de Tabasco-Campeche y tierra adentro." Estudios de Cultura Maya, v. 14 (1982): 69-118.

West, Robert, N. P. Psuty y B. G. Thom. Las tierras bajas de Tabasco en el sureste de México. Villahermosa: Gobierno del Estado de Tabasco, 1985.

\section{SOBRE LA AUTORA}

Nicoletta Maestri es doctora en Antropología (con especialización en Arqueología) por la Universidad de California, Riverside. Actualmente es becaria posdoctoral en el Instituto de Investigaciones Históricas de la UNAM. Sus líneas de investigación abarcan la arqueología y la historia del paisaje, 
los cambios en las prácticas de movilidad en el periodo prehispánico y colonial en el área maya. Entre sus publicaciones destaca "Ancient Maya Water Management: A Review of the Academic Perception of Maya Tropical Environment", en "My Life is like the Summer Rose", en Maurizio Tosi e l'archeologia come modo di vivere. Papers in Honour of Maurizio Tosi for his 70th Birthday, coord. de C. C. Lamberg-Karlovsky (Oxford, uK: B. Genito and B. Cerasetti, BAR International Series 2690, Archeopress, 2014), 457462. 


\section{Mapa 2}

Provincia de Tabasco por Melchor de Alfaro Santa Cruz, 1579

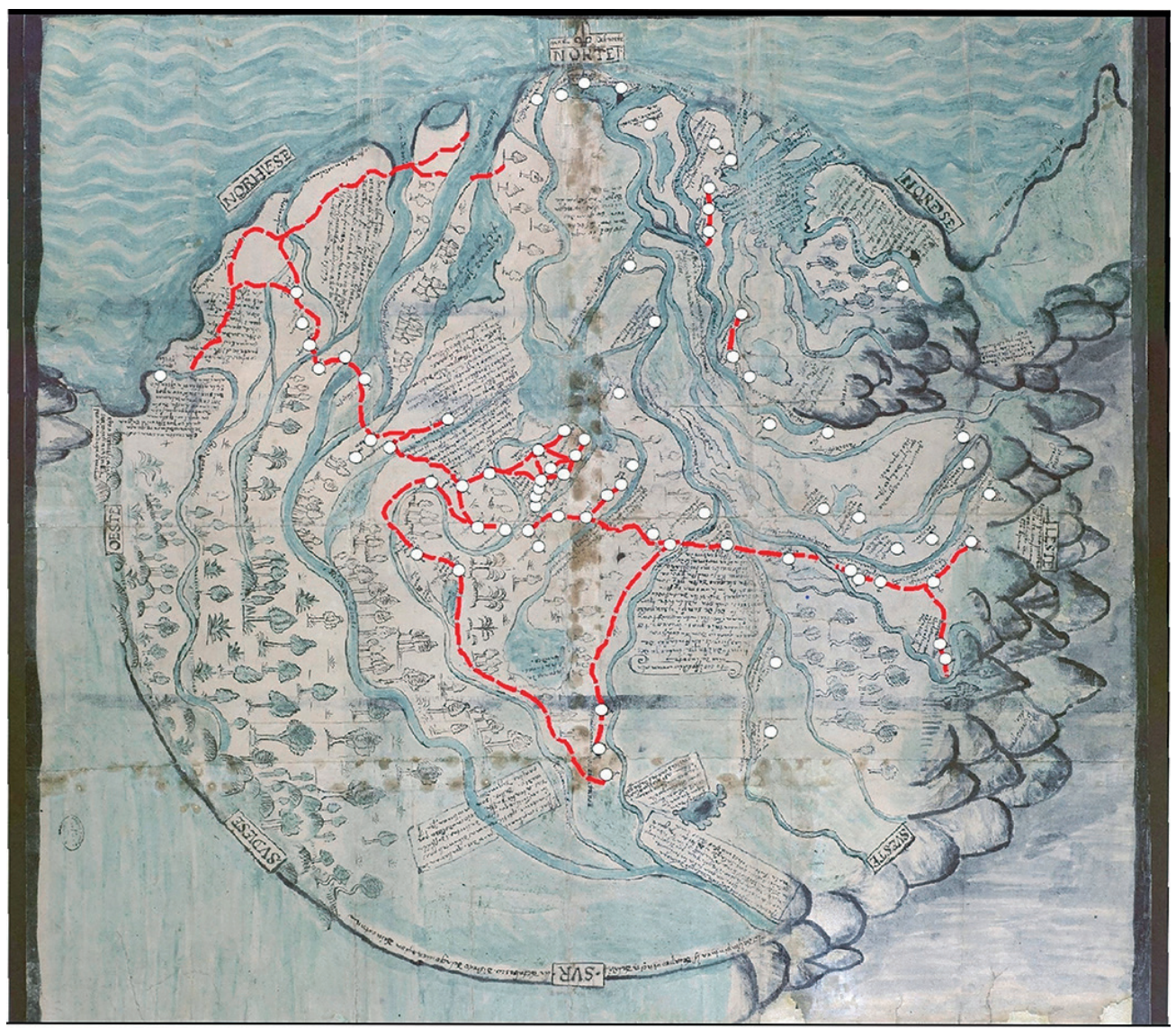

- PUEBLOS_ASC_1579

CAMINOS_ASC_1579

Fuente: AgI, Mapas y Planos, ES.41091. AGI//MP-MÉXiCo, 14. Mapa modificado por la autora, resaltando pueblos (puntos) y caminos (líneas) del siglo Xvi. Agradezco a la maestra Flor Trejo Rivera por facilitarme la imagen original. 
Mapa 3

Detalle del mapa de la Provincia de Tabasco

de Melchor de Alfaro Santa Cruz, 1579

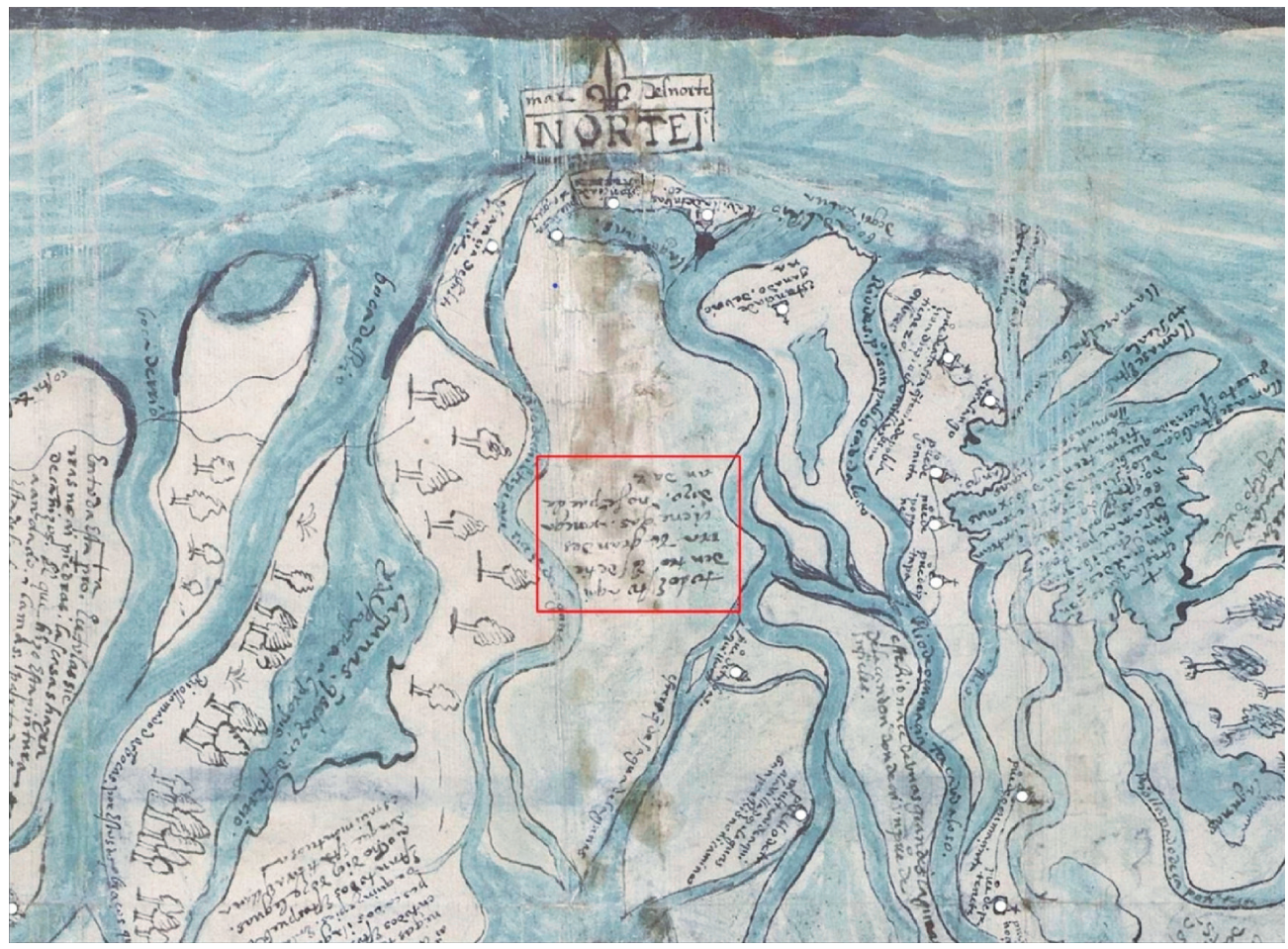

Fuente: AGI, Mapas y Planos, ES.41091. AGI//MP-MÉXICo, 14. El cartucho evidencia el texto mencionado. Mapa modificado por la autora. 